DOI: https://doi.org/10.24297/jap.v15i0.8034

\title{
Combined Cycle Consisting of Closed Processes Based Cycle Powered by A Reversible Heat Pump that Exceed Carnot Factor
}

\author{
Ramon Ferreiro Garcia ${ }^{1}$, Jose Carbia Carril ${ }^{2}$ \\ ${ }^{1}$ Ind. Eng. Dept., ${ }^{2}$ Energy and Propulsion Dept., University of A Coruna. \\ ETSNM, C/Paseo de Ronda, 51, 15011 A Coruna, Spain \\ ferreiro@udc.es; crbia@udc.es;
}

\begin{abstract}
This article deals with the task of analysing a feasible reversible combined cycle composed of a heat pump as the primary cycle and a non-condensing mode thermal engine characterized by operating under a closed processes based cycle that work by adding and releasing heat, as the secondary cycle. Two case studies are analysed and compared. According to the results, the case study based on the combination of a heat pump cycle with an organic Rankine cycle, is the paradigm of a reversible $100 \%$ efficient combined cycle. The case study based on a heat pump cycle and a reversible heating-cooling based cycle is the paradigm of a superefficient combined cycle that yields a 1.486 power ratio (PR) or $148.6 \%$ efficiency. Further, the case based on a heat pump cycle with a regenerative irreversible heating-cooling based cycle, is the paradigm of energy conversion and energy generation that yields a 1.29 PR or $129 \%$ efficiency assuming limited irreversibilities.
\end{abstract}

Keywords: Cooling-based work, Exceeding Carnot factor, First-law extension, Heating-cooling based cycles, Kelvin-Plank statement.

\begin{tabular}{|c|c|c|c|}
\hline \multicolumn{2}{|c|}{ Nomenclature } & \multicolumn{2}{|c|}{ acronyms } \\
\hline $\begin{array}{l}\mathrm{C}_{\mathrm{p}} \\
(\mathrm{kJ} / \mathrm{kg}\end{array}$ & $\begin{array}{l}\text { specific heat at constant pressure } \\
\text { K) }\end{array}$ & ah & $\begin{array}{l}\text { adding heat } \\
\text { combined cycle }\end{array}$ \\
\hline $\begin{array}{l}C_{V} \\
K)\end{array}$ & specific heat at constant volume $(\mathrm{kJ} / \mathrm{kg}$ - & $\begin{array}{l}\text { CES } \\
\text { cycles }\end{array}$ & Carnot, Ericsson and Stirling thermal \\
\hline dT & $\begin{array}{l}\text { temp. difference between two fluids (K) } \\
\text { thermal efficiency (\%) }\end{array}$ & CF & Carnot factor, Carnot efficiency \\
\hline$\eta_{c}$ & Carnot efficiency (\%) & DEC & double effect cylinder \\
\hline$\gamma$ & $\begin{array}{l}\text { polytropic exponent } \\
\text { adiabatic exponent }\end{array}$ & $\begin{array}{l}\mathrm{HCC} \\
\text { cycle }\end{array}$ & reversible heating-cooling based \\
\hline $\mathrm{I}_{C \mathrm{C}}$ & irreversibilities of the $C C_{\mathrm{RBC}-\mathrm{HCC}}$ & HEX & heat exchanger \\
\hline $\mathrm{I}_{\mathrm{T} . \mathrm{RBC}}$ & irreversibilities of the RBC turbine & rh & releasing heat \\
\hline $\mathrm{I}_{\mathrm{C} . \mathrm{RBC}}$ & irreversibilities of the RBC compressor & ORC & $\begin{array}{l}\text { organic Rankine cycle } \\
\text { heat from the low temperature }\end{array}$ \\
\hline
\end{tabular}




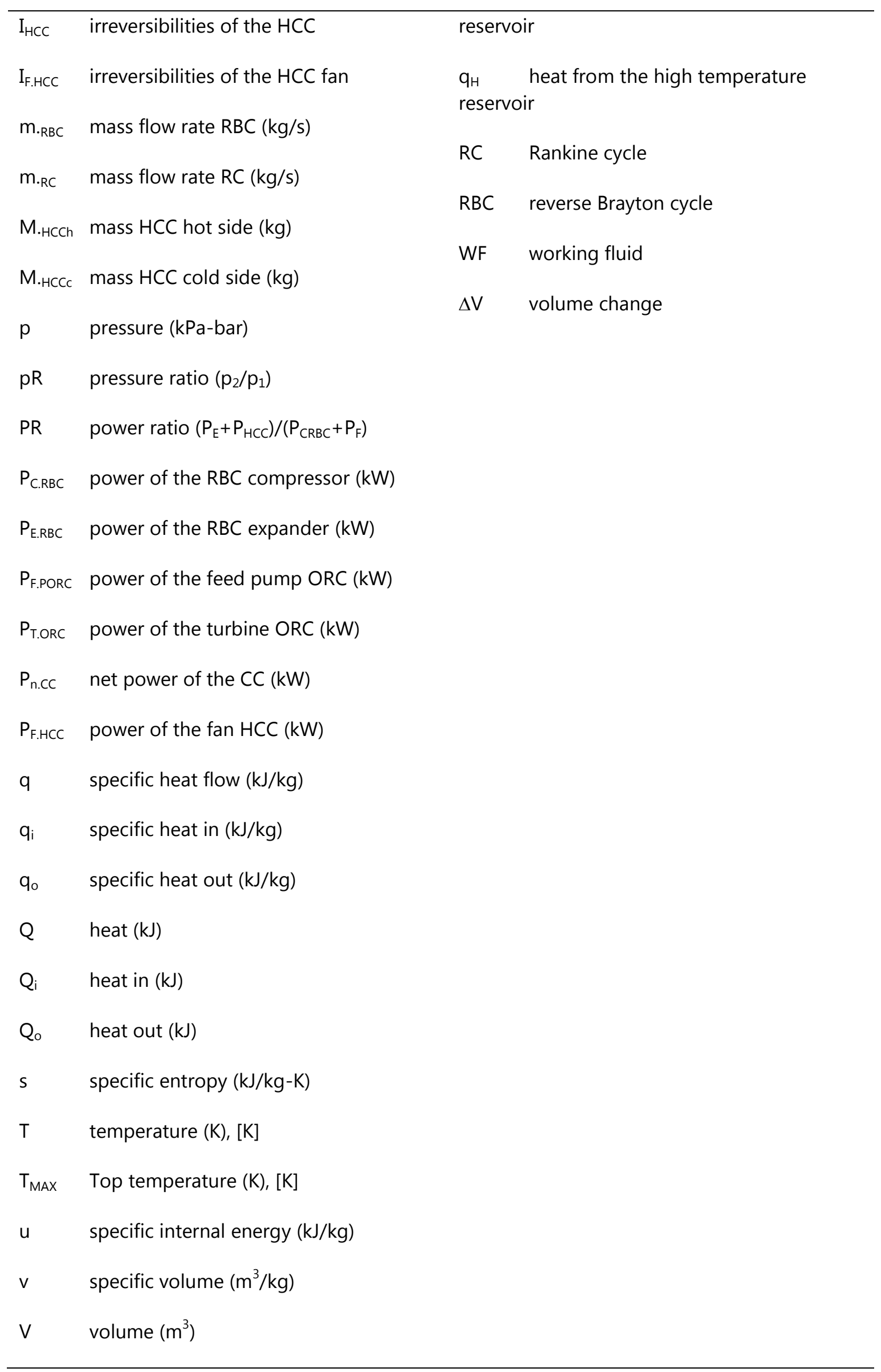




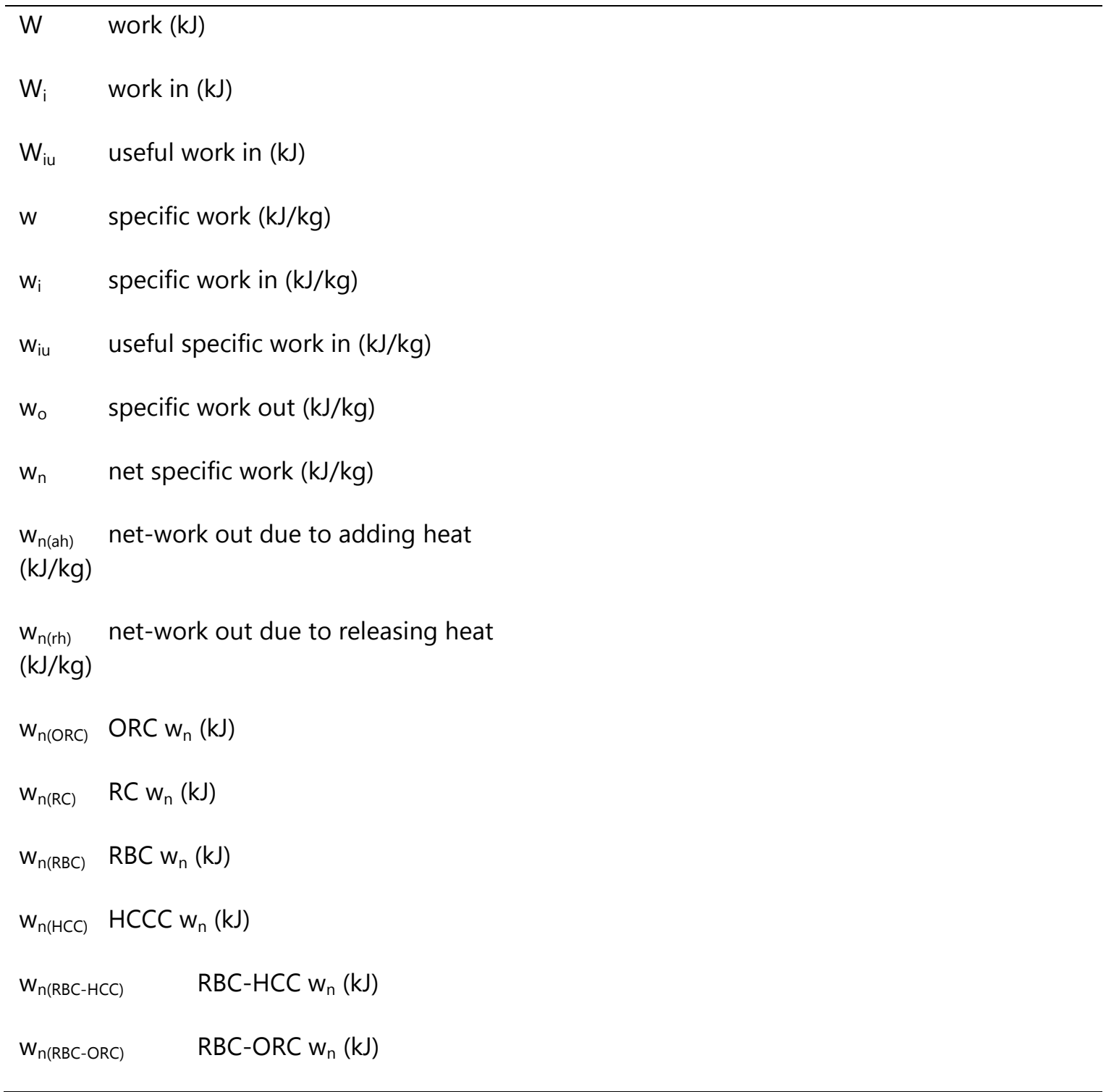

\section{Introduction}

The observable inconsistencies in the manipulation of thermal energy focused on heat-work interaction modes leads us to admit some differences between the concepts of heat conversion into mechanical work and energy generation in the form of mechanical work-work interactions. Thus, for example, taking into consideration a combined cycle consisting of a reverse Brayton cycle as the primary cycle and a conventional thermal cycle such as a Rankine cycle as the secondary cycle, both reversible, where the Rankine cycle operates with the thermal sources generated by the reverse Brayton cycle, It is observed that the amount of work applied to the compressor of the reverse Brayton cycle is equal to the work obtained from the Rankine cycle, which means that a reversible combined cycle approaches a thermal efficiency of $100 \%$.

However, if instead using a conventional Rankine cycle, a non-conventional one such as a non-conventional closed process based heating-cooling thermal cycle, characterized by a defying Carnot factor, were utilized, the amount of work obtained is greater than the work applied to the compressor of the reverse Brayton cycle (energy has been created or generated). These results are not possible according to the first and second laws. Therefore, such controversial results require rigorous analysis to detect those inconsistences that tolerate such 
flagrant violation of the fundamental laws. To begin highlighting the encountered inconsistences, let us revise briefly its antecedents and background.

\subsection{Background on low-grade heat applications unconstrained by Carnot factor}

During the present decade, some research works focusing on non-condensing type thermal cycles appeared in the work of Ferreiro et al. [1-5], which converts heat into mechanical work by undergoing only closed processes, and are characterised by a surpassing Carnot factor (CF). Evidence for exceeding the CF in thermal cycles undergoing thermodynamic transformations, based on closed processes composed of feasible heatwork interactions that fulfil the second law, is the motivation for a deeper analysis. Mentioned thermal cycles are particularly useful for small temperature differences between high- and low-temperature reservoirs. For instance, the thermal efficiency for a high- and low-temperature reservoir of 320 and $305 \mathrm{~K}$ respectively is $25.4 \%$ with hydrogen, $36.3 \%$ with helium and $38.1 \%$ with argon as the working fluids. The Carnot cycle thermal efficiency for the same temperatures is $7.8 \%$ (these efficiencies are unprecedented).

The authors published in [1] research to show that a closed processes-based cycle operating with low grade heat sources can provide high-thermal efficiency. They described in [2] an application based on ocean thermal energy, assuming a difference of $20(\mathrm{~K})$ between the top and bottom cycle temperatures with helium as the working fluid, which obtained a thermal efficiency of $80.63 \%$. In contrast, the Carnot cycle thermal efficiency of the same cycle approaches only $6.66 \%$. Another interesting application of this trilateral cycle consists of a secondary cycle operating with the residual heat rejected from the steam condenser of a power plant, which yielded thermal efficiencies over $70 \%$; the net efficiency of the power plant will therefore reach unmatched levels of performance [3]. In [4] the researchers explored a closed based thermal cycle to compare adiabatic and isothermal expansions, where the Carnot factor is surpassed at both low and medium temperatures. In [5] they also studied ways to select a working fluid for each temperature range in order to achieve high efficiencies under isothermal expansion. The efficiencies achieved in [1-5] are comparably higher than conventional thermal cycles that exploit waste heat energy.

The relevance of researching low-grade heat or waste heat applications is governed by the fact that a vast amount of heat energy is available at negligible cost within the range of medium and low temperatures; the drawback being that existing thermal cycles cannot make efficient use of such heat because they are mainly based on CES (Carnot-Ericsson-Stirling) cycles limited by Carnot constraints. Therefore, Ferreiro et al. [6] proposed a thermodynamic study of regenerative Otto-based cycles with zero NOx emissions operating with adiabatic and polytropic expansion, where the Carnot factor is surpassed. They also presented the results of a study dealing with the analysis of the energy and entropy of closed adiabatic expansion based trilateral cycles where the Carnot factor is also surpassed.

A large amount of work has therefore been carried out into cooling based reverse Carnot cycle systems, including rotary desiccant air conditioning systems, and most report that the Carnot factor is surpassed [8-13]. She et al. [8] therefore proposed a new energy-efficient refrigeration system sub-cooled by liquid desiccant dehumidification and evaporation. This system is characterised by the capacity of the liquid desiccant system to produce very dry air for an indirect evaporative cooler, where results have shown that the proposed hybrid vapour compression refrigeration system achieves significantly higher COP (coefficient of performance) than conventional vapour compression refrigeration systems, and even higher than the reverse Carnot cycle at the same conditions of operation. In this way, Mandegari et al. [9] performed an exergy analysis and optimization of a dehumidification desiccant wheel (DW) system. The optimal value of the parameters used demonstrates that when exergy destruction effectiveness is selected as the objective function, the regeneration air velocity is an optimal decision variable. Similarly, Jani. et al. [10] developed an energy and exergy analysis of a solid desiccant vapour compression hybrid air conditioning system, where the rotary desiccant dehumidifier and heater are major contributors to the exergy performance of the system. They suggest the analysis provides knowledge beneficial in determining the theoretical upper limit of the system performance. 
Kim et al. [11] proposed the integration of a liquid desiccant system into an evaporative cooling-assisted 100\% outdoor air system. Simulation results show that the proposed system consumes $51 \%$ less cooling energy compared to the conventional system. Yinglin et al. [12] experimentally tested a conventional liquid desiccantvapour compression hybrid air-conditioning system and developed a corresponding mathematical model to analyse the effect of the concentrated solution branch in the solution-solution heat exchanger on the cooling capacity of the evaporator. The results show that the percentage of cooling capacity loss of the evaporator exceeds $10 \%$, with a small concentration difference of $1.5 \%$ in the conventional air-conditioning system. Cui et al. [13] proposed a compact desiccant-evaporative heat and mass exchanger by combining the benefits of the regenerative indirect evaporative cooling and liquid desiccant dehumidification. In this instance, the model displayed a clear agreement with the experimental findings with a maximum discrepancy of $8 \%$. Furthermore, simulation results showed that the outlet temperature of the product air was affected by the working-tointake air flow rate ratio and the dimensionless channel length, while the outlet humidity ratio of the product air was influenced by the length of the liquid desiccant film and the dimensionless channel length.

In the thermochemical field, Van Den Einde [14] reviewed the logic of the second law that establishes the kinetic energy transfer of the ideal gas Carnot cycle as a universal limit on the convertibility of heat to work in a cyclical process. The author observed that the positive excess heat of a reaction between a supercritical solvent and a solid solute enables a closed-power cycle to access input heat from successive thermal reservoirs below its normal temperature, where the heat to work conversion rate of the cycle is compared to the summed work output of ideal gas Carnot cycles using the same amount of heat from the same reservoirs. The results show that the energy conversion rate of the cycle exceeds the isentropic potential of its input heat to do work. Van Den Einde [15] also investigated the potential for the regeneration of exhaust heat from a complete Rankine cycle. The working fluid produced in a closed condensing cycle consists of a low boiling point solvent and a solid solute, where the solution reaction yields a positive excess enthalpy in the solvent's subcritical liquid range near the bottom temperature of the cycle and exhibits retrograde solubility in the solvent's supercritical fluid range near the top temperature of the cycle. In doing work, while adding and releasing heat from a working fluid by means of a reciprocating double effect cylinder, Ferreiro et al. [16] carried out an analysis of the energy produced by closed adiabatic expansion-based trilateral cycles where the Carnot factor is surpassed when adding and releasing heat. Since the observable inconsistencies in the manipulation of thermal energy focused on heat-work interaction modes leads us to admit some differences between the concepts of heat conversion into mechanical work and energy generation in the form of mechanical work-work interactions, a deeper analysis is performed on a combined cycle that uses a nonconventional closed-process based heating-cooling thermal cycle as the secondary cycle, characterised by a defying Carnot factor, where the amount of work obtained is apparently greater than the work applied to the primary cycle of the combined cycle. Furthermore, as these results are not possible according to the first and second laws, such controversial results require a rigorous analysis to detect those inconsistences that tolerate such flagrant violation of the fundamental laws. Thus, the next section describes preliminary concepts regarding the problem-solving strategy. Section 3 is devoted to the analysis of a case study based on a combined cycle composed by a reverse Brayton as the primary cycle and a closed-processes based heatingcooling reciprocating engine as the secondary cycle. In Section 4 we analyse and discuss the results and finally, in last section, some conclusions are highlighted.

\section{Energy conversion versus energy generation: Problem statement and solving strategy}

As commented on in the introduction, recently thermal engines have been obtained that outperform Carnot. [1-7] Subsequently, thermal engines have been obtained that are capable of performing mechanical work due to releasing heat from the cycle to the heat sink at no cost [2-3]. Their performance is likely to overlap with the performance achieved by conventional thermal engines that exceed Carnot doing work only due to adding heat. As a consequence of such findings, it was observed that a fundamental law, such as the law of conservation of energy, needs to be revised and amended in order to fulfil the first law of thermodynamics [16]. This phenomenon has been observed when dealing with thermal cycles, in which there is a heat-work interaction mode in which useful adiabatic work is done by means of a compression-based contraction 
process, characterised by doing useful work while increasing simultaneously the internal energy into the same closed process. Such phenomenon violates the principle of energy conservation as it has been stated so far, and consequently the first law. In relation to this topic, it seems reasonable to reflect on the possibility of overcoming the efficiency of the conventional reversible thermal cycles, with the aim of moving toward the hypothetical attainment of perpetual motion machines.

Therefore, given a reversible thermal engine consisting of a conventional combined cycle composed by a reverse Brayton cycle as primary cycle and a Rankine cycle as secondary cycle, according to the statements of Clausius and Kelvin-Planck, it should operate within a thermal efficiency very close to the unit. Thus, if a reversible engine is available that is capable of operating above the thermal efficiency of a conventional reversible engine (close to the unit), it can be assumed that its performance should be higher than that of the conventional reversible engine (greater than the unit). Then one has to ask the question of whether such an engine is theoretically possible and what architecture it adopts. This reasoning leads us towards the development and implementation of hypothetical perpetual motion engines.

Conventional procedures used so far for the analysis of thermal cycles are based on compliance with the principle of energy conservation and compliance with the $2^{\text {nd }}$ law of thermodynamics. Thus, if a reversible thermal cycle that converts thermal energy into mechanical work provides more mechanical work than the energy absorbed to perform such mechanical work, one can only interpret such a result as:

a) energy can be created, which is neither understandable nor acceptable;

b) the laws of physics on which the analysis procedure is based require a severe overhaul, or at least a major revision.

Thermal energy conversion is a well-accepted fact at the cost of transferring heat energy from a hot heat source reservoir to a cold heat sink reservoir while increasing the entropy of transferred energy.

The implication and consequence of this fact is that after a sufficient large time horizon, all known hot energy would be converted into a cold reservoir of very low-grade heat and usefulness energy of enormous entropy that could not be used according to the statements of Clausius and Kelvin-Planck as well as the known conventional techniques. Therefore, the objective is to develop an analytical or theoretical basis to design a power cycle consisting of a combined cycle, in which the thermal reservoirs are provided by the primary cycle, characterized by providing the conventional hot and cold heat reservoirs. Thus, the combined cycle is composed of a primary cycle implemented by a reverse Brayton followed by a secondary cycle consisting of a closed-process based thermal cycle characterized by the performance of mechanical work by adding and releasing heat to/from a working fluid. According the conventional thermodynamics, the second law requires two heat reservoirs of infinite capacity (the high-temperature reservoir or power source and the-low temperature reservoir or heat sink). However, it will be shown that the proposed combined cycle does not need such infinite heat reservoirs, but a heat source and heat sink generated by the reverse Brayton cycle. This cycle belongs to a combined cycle, where the secondary cycle is implemented by means of a thermal engine capable of transforming heat and cold into mechanical work, where heat and cold are supplied from the hot and cold thermal sources provided by the primary thermal cycle.

The reversible combined cycle exhibits such a structure that while the primary cycle consists of a reverse Brayton cycle operated with power obtained from the secondary cycle. The primary cycle provides the necessary high-temperature heat source and the low-temperature heat sink, conventionally known as the heat source and the heat sink reservoirs. The secondary cycle consists of an unconventional thermal cycle which operates with the heat source and heat sink reservoirs, provided by the primary cycle, which is characterised by yielding more work than is necessary to operate the reverse Brayton cycle, so that some energy has been created; this is a flagrant violation of the fundamental laws of physics, such as the law of conservation of energy. 


\subsection{Conventional and fundamental statements of thermodynamics}

The first principle of thermodynamics and consequently the principle of conservation of energy would be violated if it were possible to obtain useful mechanical work from a machine, which absorbs less energy than it releases. In contrast, the statements involving the $1^{\text {st }}$ law, also known as the "principle of the conservation of energy", states that the relationships among various forms of energy and energy interactions. Therefore, based on conventional experimental observations so far, the $1^{\text {st }}$ law of thermodynamics states that "energy can be neither created nor destroyed; it can only change forms". In another way, the statements involving the $2^{\text {nd }}$ law express the conditions that satisfy the heat transfer properties. Thus, Clausius' statement stated that "it is impossible for any system to operate in such a way that the sole result would be an energy transfer by heat from a cooler to a hotter body". Furthermore, such statement undergoes the meaning: "it is impossible to construct a device that operates in a cycle and produces no effect other than the transfer of heat from a lower-temperature body to a higher-temperature body".

In the same way Kelvin-Planck stated that "It is impossible for any device that operates on a cycle to receive heat from a single reservoir and produce a net amount of work".

However, according to the last advances based on doing work by releasing heat as shown in $[1,2,16]$, and the results of the analysis carried out in this work, amendments to the Clausius and Kelvin-Plank statement may be required, when considering the contribution of doing work while releasing heat to a heat sink.

\subsection{Considerations on energy manipulation strategies}

The energy balance according to the equation of conservation of energy can be established according to

- a single process balance, or

- a cycle processes balance as the case of a multiple-process balance

Taking into account the observations, closed-process based heat-work interaction modes occur when obeying the causality law, which for the case of a cycle undergoes more than a closed transformation, although the law of conservation of energy must be satisfied for every closed process. That is, for a closed process the first law yields

$\sum q_{i}-\sum q_{o}+\sum w_{i}-\sum w_{o}=\Delta u$

while for a closed processes based cycle, the first law yields

$\sum q_{i}-\sum q_{o}+\sum w_{i}-\sum w_{o}=0$,

which implies that

$\sum q_{i}-\sum q_{o}=\sum w_{o}-\sum w_{i}$,

commonly expressed as the net cycle work, $w_{n}$ where

$\sum q_{i}-\sum q_{o}=w_{n}$

which is considered as the paradigm of the net mechanical work, since according the first law, as defined so far, it is assumed as the net cycle work. However, the findings published in [16], summarised in Table 1 and depicted in Fig. 1, contradict the first principle and the principle of the conservation of energy. 
$w_{\text {n(ah) }}=w_{o_{-} \text {exp }}=C v \cdot\left(T_{2}-T_{3}\right)$

$w_{\text {n(ah) }}=w_{o_{-} \text {exp }}=C v \cdot\left(T_{2}-T_{3}\right)$

$w_{n(r h)}=w_{\text {iu }}=w_{o_{-} c o n t}=C v \cdot\left(T_{1}-T_{4}\right)$

$w_{n}=C v \cdot\left(T_{2}-T_{3}\right)+C v \cdot\left(T_{1}-T_{4}\right)$

Table 1. The energy balance for the three thermal cycles unconstrained by Carnot factor, in which those cycles that operate by releasing heat violate the first law, such as is stated conventionally [16]

\begin{tabular}{|c|c|c|c|c|c|}
\hline \multicolumn{2}{|l|}{ Cycle type } & \multicolumn{2}{|l|}{$1^{\text {st }}$ law fulfilment } & \multicolumn{2}{|c|}{ Net-work } \\
\hline trilateral & (ah) only & $q_{i}-q_{o}=w_{n(h a)}$ & $Y$ & $w_{n(a h)}=q_{i}-q_{0}$ & $w_{n(a h)}=q_{12}-q_{31}$ \\
\hline trilateral & (rh) only & $q_{i}-q_{o}=-w_{n(r)}$ & $\mathrm{N}$ & $w_{n(r h)}=q_{0}-q_{i}$ & $w_{n(r h)}=q_{34}-q_{31}$ \\
\hline quadrilateral & (ah) and (rh) & $q_{i}-q_{o}=w_{n(a h)}-w_{n(r h)}$ & $\mathrm{N}$ & $w_{n}=w_{n(a h)}+w_{n(r h)}$ & $w_{n}=q_{12}-q_{31}+q_{34}-q_{31}$ \\
\hline
\end{tabular}

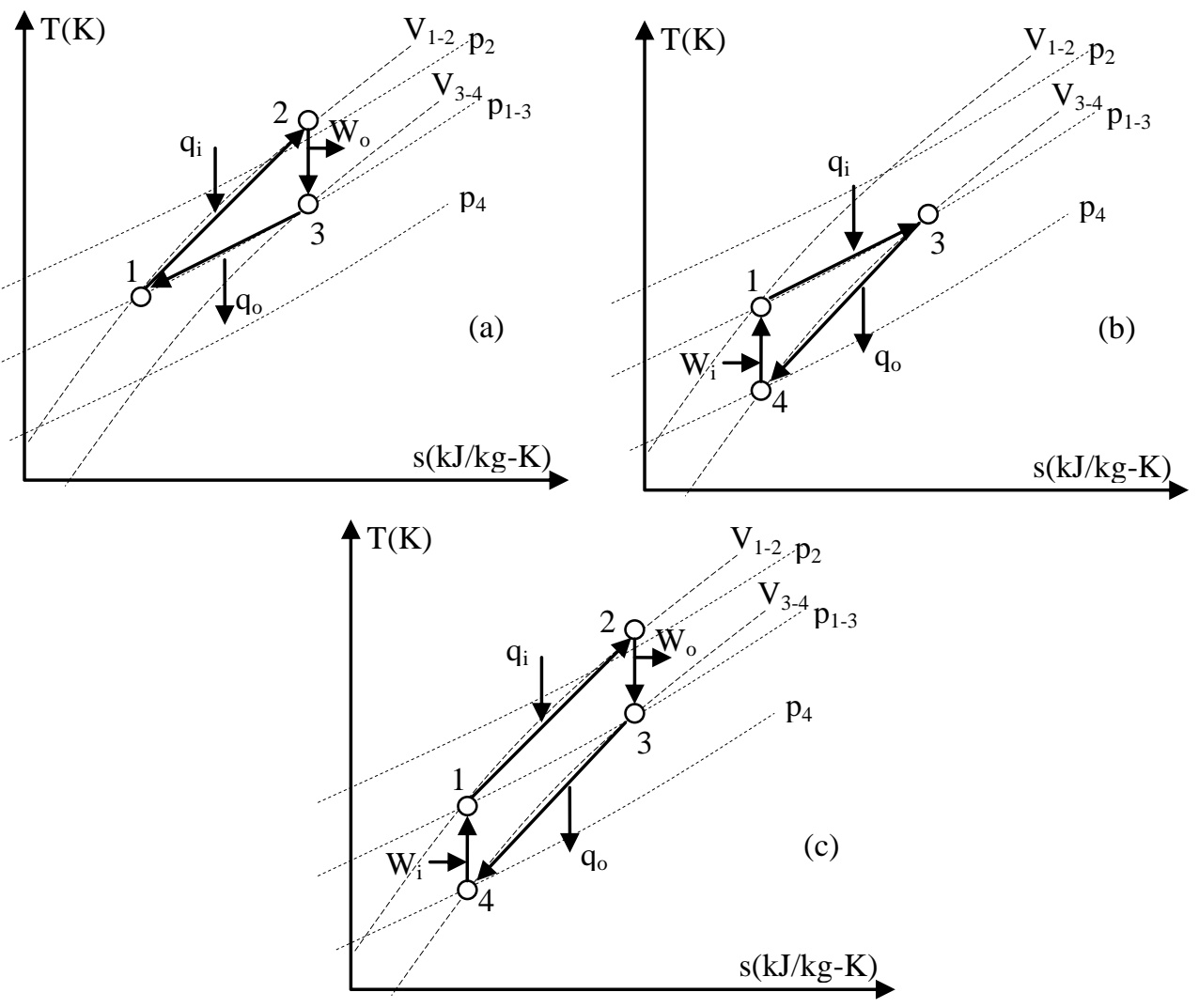

Fig. 1. The T-s diagrams of the three thermal cycles unconstrained by a Carnot factor [16]. (a) Corresponds to a cycle that does work by adding heat only. (b) Corresponds to a cycle that does work by releasing heat only. (c) Corresponds to a cycle that does work by adding and releasing heat. 
The consequences derived from the observed facts are going to be proved using a comparative analysis between two reversible combined cycles:

a) a combined cycle composed of a reversible reverse Brayton cycle (RBC) as the primary or topping cycle and a reversible organic Rankine cycle (ORC) as the secondary or bottoming cycle which undergoes the structure shown in Fig. 2;

b) a combined cycle composed of a reversible RBC as the top cycle and a reversible quadrilateral heatingcooling based thermal cycle (HCC) as the secondary cycle commented in the bottom row of the Table 1, which obey the structure shown in Fig. 3.

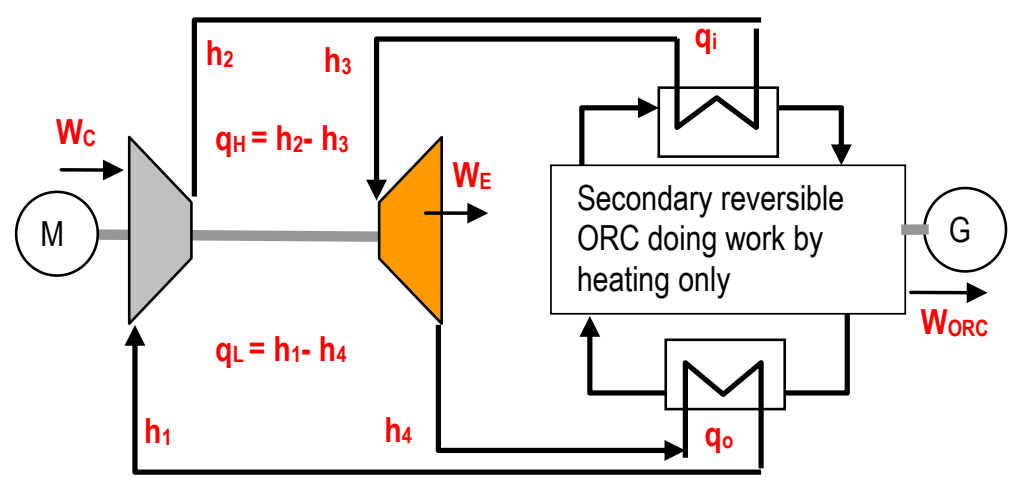

Fig. 2. The structure of the reversible combined cycle composed by a RBC as the primary cycle and an ORC as the secondary cycle.

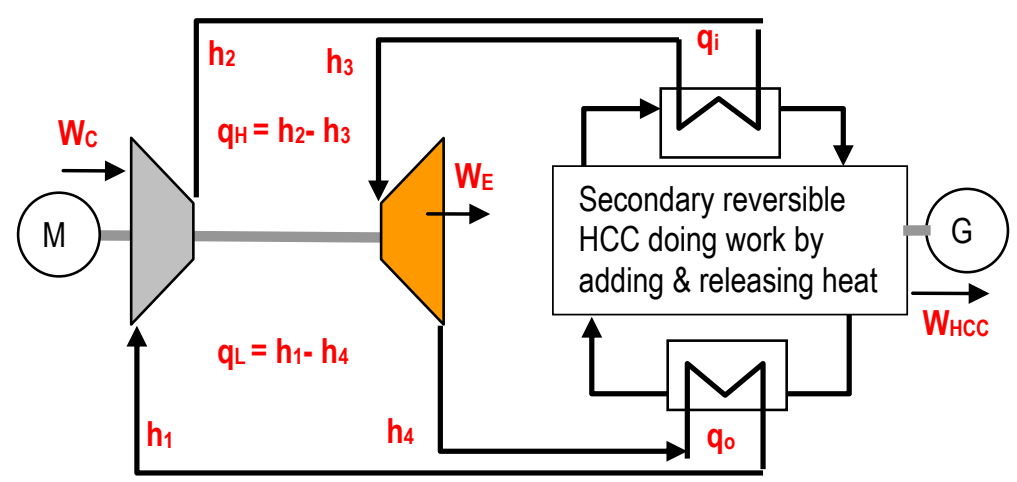

Fig. 3. Combined cycle, showing the primary cycle composed of an RBC, which provides the heat source and heat sink for the secondary cycle, composed of a closed-process based reciprocating engine characterised by converting heat to work while heating and releasing heat.

While for closed-processes based cycles the first law is expressed as shown in (1)-(4), for open processes based cycles, the first law is as follows:

$\sum h_{i}-\sum h_{o}+\sum w_{i}-\sum w_{o}=0$,

which implies that

$\sum h_{i}-\sum h_{o}=\sum w_{o}-\sum w_{i}$ 
commonly expressed as the net cycle work, $w_{n}$ where

$\sum h_{i}-\sum h_{o}=w_{n}$

\subsection{The analytic structure of the combined cycle (CC)}

The CC is composed of a reversible reverse Brayton cycle (RBC) as the primary cycle and a reversible organic Rankine cycle (ORC) shown in Fig. 2, or a non-conventional closed-process based heating-cooling thermal cycle as the secondary cycle denoted as reversible heating-cooling based cycle (HCC), shown in Fig. 3 .

\section{The primary cycle: a reversible $\mathrm{RBC}$}

The compressor, the expander and the heat exchangers devoted to the high- and low-temperature heat sources of the secondary cycle composes of a RBC. The energy balance of the reversible RBC is described with equation (11) and (12) as

$\sum h_{i}-\sum h_{o}+\sum w_{i}-\sum w_{o}=h_{1}-h_{2}+h_{3}-h_{4}+w_{c}-w_{E}=0$

$h_{1}-h_{2}+h_{3}-h_{4}+w_{c}-w_{E}=\left(h_{1}-h_{4}\right)-\left(h_{2}-h_{3}\right)+w_{c}-w_{E}=q_{L}-q_{H}+w_{c}-w_{E} \rightarrow q_{H}-q_{L}-w_{c}+w_{E}=0$

Thus, the net-work due to the RBC is given as

$w_{n(R B C)}=-w_{c}+w_{E}$

\section{The secondary cycle as the conventional option: a reversible ORC}

Description of the ORC. Energy balance based on first law as stated conventionally as

$\sum q_{H}-\sum q_{L}-w_{n(O R C)}=q_{i}-q_{o}-w_{n(O R C)}=0$

Thus,

$w_{n(O R C)}=q_{i}-q_{o}$

The secondary cycle as the innovative option: The HCC, a reversible heating-cooling based cycle

Description of the HCC.

The energy balance is based on the extended first law as stated in [16]. This consideration is due to the special characteristics of the HCC engine described in [16]. Therefore, the first principle yields

$\sum q_{i}-\sum q_{o} \neq w_{n(H C C)} \rightarrow q_{i}-q_{o}=w_{n(a h)}-w_{n(r h)}$

$w_{\mathrm{n}(\mathrm{HCC})}=w_{\mathrm{n}(\mathrm{ah})}+w_{\mathrm{n}(\mathrm{fH})}=C v \cdot\left(T_{2}-T_{3}\right)+C v \cdot\left(T_{1}-T_{4}\right)$

\section{The CC based on the RBC-ORC}

Since $w_{n(R C)}=-w_{c}+w_{E}$, then energy balance based on the first law by combining (12) and (13) yields

$q_{H}-q_{L}-w_{c}+w_{E}=q_{i}-q_{o}-w_{n(O R C)}=0$ 
Thus, considering $q_{H}-q_{L}=q_{i}-q_{o}$ then it follows that

$-w_{c}+w_{E}=-w_{n(O R C)}=0$

and

$w_{c}=w_{E}+w_{n(R C)}$

Consequently, the net-work due to the CC composed by the RBC-RC is given as

$w_{n(\mathrm{RBC}-\mathrm{ORC})}=w_{n(R B C)}+w_{n(\mathrm{ORC})}=-w_{c}+w_{E}+w_{c}-w_{E}=0$

which is a valid test that confirms that the thermal efficiency of a reversible combined cycle based on the RBC$\mathrm{RC}$ is $100 \%$, something not considered so far, which is not restricted by the Carnot factor as confirmed in [1-7] and $[16-17]$.

\section{The CC based on the RBC-HCC}

The energy balance based on the extended first law as stated in [16] is obtained as follows: combining (12) and (15), the net-work of the combined cycle is given as

$w_{n(\mathrm{RBC}-\mathrm{HCC})}=w_{n(R B C)}+w_{n(H C C)}=\left(-w_{c}+w_{E}\right)+\left(w_{n(a h)}+w_{n(r h)}\right)$

however, using (18) as $w_{n(R C)}=w_{c}-w_{E}$ in (19), then (20) yields

$w_{n(R B C \cdot H C C)}=\left(-w_{n(R C)}\right)+\left(w_{n(a h)}+w_{n(r h)}\right)$

Therefore, a straightforward conclusion from (21) is that:

If in (21) $\left(w_{n(a h)}+w_{n(r h)}\right)>\left(w_{n(O R C)}\right)$, then, $w_{n(R B C-H C C)}=\left(-w_{n(O R C)}\right)+\left(w_{n(a h)}+w_{n(r h)}\right)>0$

which means that some energy was created or generated, instead of converted. Equation (21) implies that the combined cycle created energy in the form of mechanical work, which is capable of being converted to heat, cold or any other form of energy.

In the case where in equation (21) the net-work $\mathrm{w}_{\mathrm{n}(\mathrm{RC})}$ is less than the net-work obtained in the secondary cycle of the combined cycle $\left(w_{n(a h)}+w_{n(r h)}\right)$, then, a flagrant violation of the first and second laws occurs.

If a combined cycle consisting of a reversible RBC and a reversible ORC operate at an efficiency close to $100 \%$, then a combined cycle consisting of a reversible RBC and a non-conventional thermal cycle that exceeds the Carnot factor, must provide a thermal efficiency of more than $100 \%$.

On the basis of the findings presented in (19), (21) and (22) it can be said that the energy balance of the reversible CC is a controversial result. Such an extraordinary phenomenon has never been observed before, and has severe implications for the energy balance of closed-process based cycles conducted by heat addition and heat releasing as stated in [16]. Fortunately, such consequences imply a significant advantage, thanks to the effect of releasing heat while obtaining useful work, associated with the finite thermal reservoirs generated by a reversible reverse Brayton cycle. In any case, standardising the definitions derived from the new findings, requires the consensus of an international committee of experts to define precisely the principles that should be stated. 


\section{A case study}

In order to validate the theoretic findings, it is proposed to investigate a feasible case which deals with the study of two thermal engine structures consisting of two reversible combined cycles: a RBC-ORC and a RBC$\mathrm{HCC}$, which allows us to analyse and compare the consequences derived from the application of equation (19) for a reversible RBC-ORC and (21) for a reversible RBC-HCC. The secondary cycles, ORC and HCC of the studied CCs are depicted in Fig. 4. The study was carried out for helium as the working fluid, assumed as an ideal gas when dealing with reversible cycles and a real gas when irreversibility is considered in line with the data provided by Lemmon et al. [17].
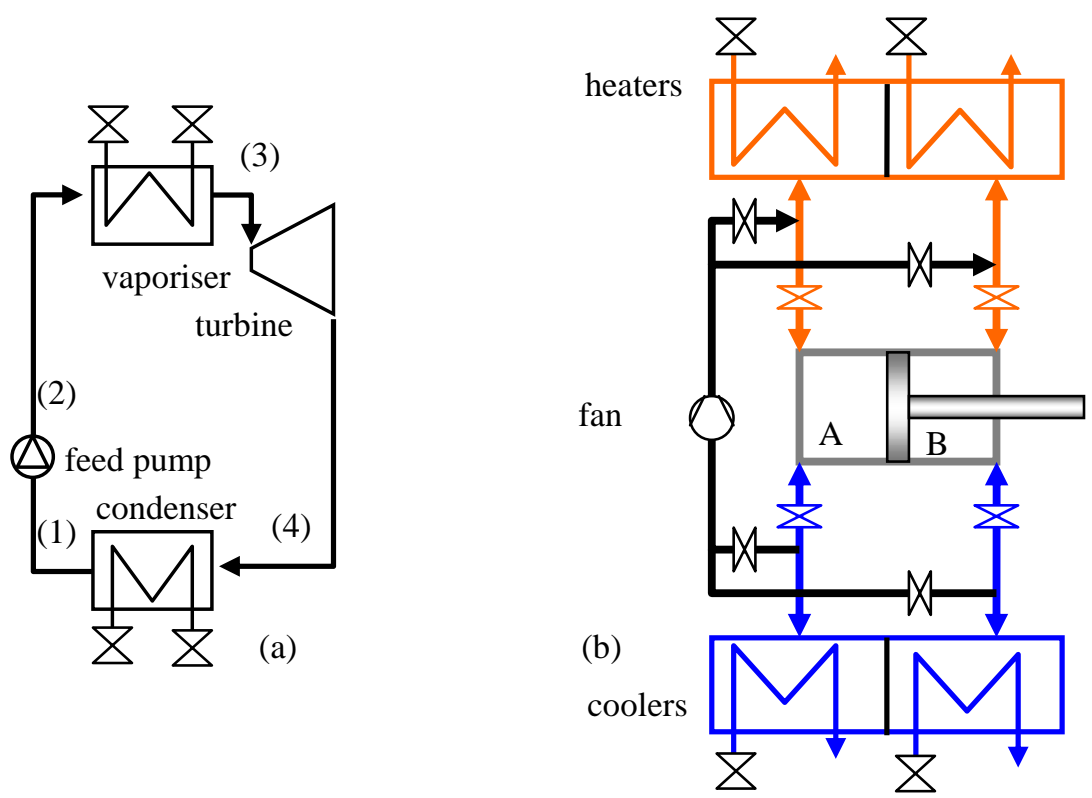

Fig. 4. Secondary cycle of the combined cycle, a RC or an ORC. (a) The conventional reversible ORC. (b) The non-conventional closed-process based heating-cooling thermal cycle implemented by means of a reciprocating double effect engine, a HCC.

While the cycle shown in Fig. 4(a), which represents a conventional ORC, does not need any special description, the case of Fig. 4(b) represents the proposed HCC illustrated in Fig. 5, which is a non-conventional closed-process based heating-cooling thermal cycle implemented by means of a reciprocating double effect engine, whose fundamentals are described in [16]. Therefore, in order to deepen their knowledge, the associated thermal cycle is described in more detail.

Table 2. Path functions associated with the quadrilateral cycle legs and for both cylinder chambers as shown in Fig. 5(d)

\begin{tabular}{|l|l|l|l|}
\hline \multicolumn{2}{|c|}{ Cylinder chamber A } & \multicolumn{2}{c|}{ Cylinder chamber B } \\
\hline Cycle leg & Closed process based path function & Cycle leg & Closed process based path function \\
\hline $1-2$ & Isochoric (adding heat at const. vol.) & $3-4$ & \\
\hline $2-3$ & Adiabatic (useful work out) & $4-5$ & Isochoric (releasing heat at const. vol.) \\
\hline $3-4$ & & $5-6$ & Adiabatic (useful work in) \\
\hline
\end{tabular}




\begin{tabular}{|l|l|l|l|}
\hline $4-5$ & Isochoric (releasing heat at const. vol.) & $6-1$ & \\
\hline $5-6$ & Adiabatic (useful work in) & $1-2$ & Isochoric (adding heat at const. vol.) \\
\hline $6-1$ & & $2-3$ & Adiabatic (useful work out) \\
\hline
\end{tabular}

This study is based on the achievements outlined in Subsection 2.2 and 2.3. It deals with the modelling task and analysis described there, according to the thermodynamic model. The study related to the secondary cycle, the HCC of the CC, analyses a double effect cylinder that performs the thermal cycles shown in Tables 3, 6 and 9, follows the engine structure shown in Fig. 5 and the T-S diagram in Fig. 5(c). The study was carried out with helium as the working fluid, assumed as an ideal gas in the case of reversible analysis and a real gas in the case of irreversible analysis, in line with data provided by Lemmon et al. [17].

The combined cycle object of the present study consists of a primary cycle, the RBC, which is responsible for providing the thermal reservoirs of high and low temperatures (heat source and heat sink), which supply heat and cold to the secondary cycle composed of the HCC cycle. Basic definitions inherent to this study include the following two concepts:

-Power ratio (PR) is the ratio of the net secondary cycle power (HCC-RC or ORC) to the net primary cycle power (the RBC).

-Pressure ratio $(p R)$ is the ratio of the outlet pressure to the suction pressure of the RBC compressor.

In what follows in this study, the reversible RBC-ORC in Section 3.1 must yield a thermal efficiency close to $100 \%$ (is not Carnot dependent, so that it is unconstrained by the Carnot factor). According to such a result, the analysis of the reversible RBC-HCC carried out in Subsections 3.2 and 3.3, should surpass such value, which theoretically violates the fundamental laws.

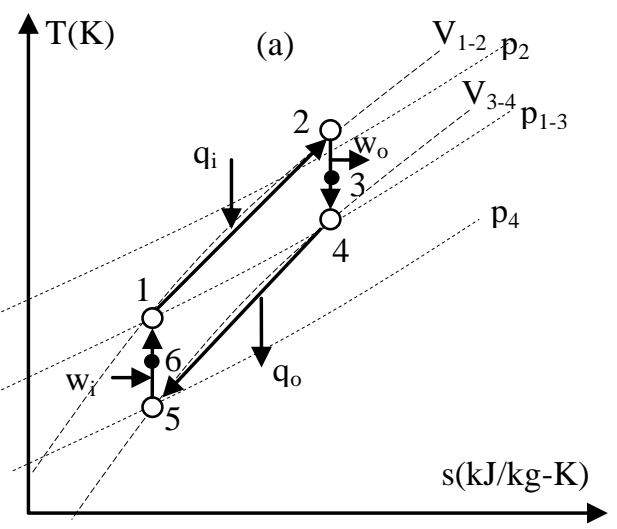

(b)

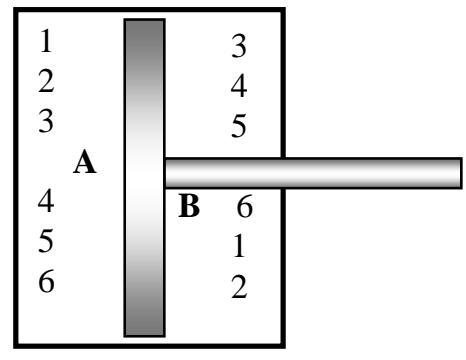

Fig.5. The basic structure of the proposed HCC thermal cycle: (a) the T-S diagram of the quadrilateral cycle performing work by heating and releasing heat for cylinder chamber $A_{;}(b)$ the simultaneous state points of the T-S diagram for cylinder chamber A and cylinder chamber B.

\subsection{The reversible CC based on $\mathrm{RBC}-\mathrm{ORC}$}

The CC analysed in this section consists of a RBC as the primary cycle and an ORC as the secondary cycle referred to in Fig. 6 . The data processed for both the primary and secondary cycles (the reversible RBC and the reversible ORC operating with ideal helium and ethane respectively) are shown in Table 3. 


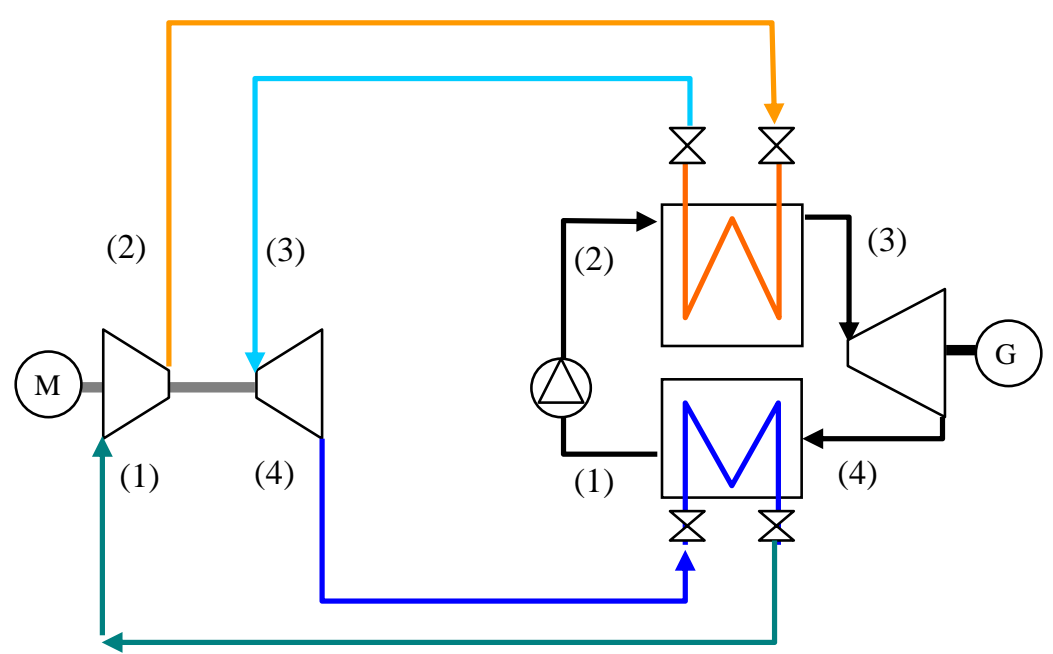

Fig. 6. Detailed structure of the reversible CC composed by a RBC as the primary cycle responsible for providing the heat source and the heat sink reservoirs to the ORC and the ORC as the secondary cycle.

Analysis with the data shown in Table 3 has been performed for the conditions with the highest performance as a function of the pressure ratio (pR). The results of the analysis are depicted in Table 4. Here, the power of the RBC compressor, the power of the RBC expander, the power of the ORC feed pump, the power of the ORC turbine, the pressure ratio, the power ratio, the mass flow rate of the $R B C$, the mass flow rate of the $O B C$ and the temperature difference of the heat exchangers are shown.

Table 3. The parameters of the CC composed of a reversible RBC with helium and a reversible ORC with ethane

\begin{tabular}{lcccccccccc}
\hline \multicolumn{1}{c}{$\mathrm{RBC}$} & \multicolumn{1}{c}{$\mathrm{ORC}$} \\
\hline point & $\mathrm{T}$ & $\mathrm{p}$ & $\mathrm{h}$ & $\mathrm{v}$ & $\mathrm{s}$ & $\mathrm{T}$ & $\mathrm{p}$ & $\mathrm{h}$ & $\mathrm{v}$ & $\mathrm{s}$ \\
& $\mathrm{K}$ & $\mathrm{kPa}$ & $\mathrm{kJ} / \mathrm{kg}$ & $\mathrm{m}^{3} / \mathrm{kg}$ & $\mathrm{kJ} / \mathrm{kg} \cdot \mathrm{K}$ & $\mathrm{K}$ & $\mathrm{kPa}$ & $\mathrm{kJ} / \mathrm{kg}$ & $\mathrm{m}^{3} / \mathrm{kg}$ & $\mathrm{kJ} / \mathrm{kg} \cdot \mathrm{K}$ \\
& & & & & & & & & & \\
1 & 305.2 & 100 & 1590 & 6.343 & 28.13 & 305.3 & 4871 & -242.7 & 0.004480 & -1.752 \\
2 & 341.1 & 132 & 1777 & 5.370 & 28.13 & 340.5 & 14000 & -210.3 & 0.003152 & -1.752 \\
3 & 340.6 & 132 & 1774 & 5.363 & 28.12 & 341.0 & 14000 & -208.7 & 0.003162 & -1.747 \\
4 & 304.8 & 100 & 1588 & 5.335 & 28.12 & 305.3 & 4871 & -241.3 & 0.004525 & -1.747 \\
\hline
\end{tabular}

The overall results of the CC are computed based on the energy conservation principle. Therefore, the network, $\mathrm{Wn}(\mathrm{RBC}$-ORC) of the reversible CC is defined as

$$
\begin{aligned}
& w_{n(R B C)}=w_{C R B C}-w_{E R B C} \\
& w_{n(R C)}=w_{T R C}-w_{F P R C} \\
& w_{n(R B C-R C)}=w_{C R B C}-w_{E R B C}+w_{T R C}-w_{F P R C}
\end{aligned}
$$


Table 4. Results of the CC composed of a RBC with helium and an ORC with ethane, operating with the data of Table 2.

\begin{tabular}{lcccccccc}
\hline$P_{C . R B C}$ & $P_{E . R B C}$ & $P_{F . P O R C}$ & $P_{T . O R C}$ & $p R$ & $P R$ & $m_{R B C}$ & $m_{\text {ORC }}$ & $d T$ \\
$k W$ & $k W$ & $k W$ & $k W$ & & & $k g / s$ & $k g / s$ & $k$ \\
186.3 & 186.0 & 32.41 & 32.58 & 1.32 & 1 & 1 & 1.38 & 0.1 \\
\hline
\end{tabular}

The results predicted by means of (19) are verified according to the results of Table 4, since we assume that the cycle is reversible, the PR is 1 undergoing a pR of 1.32, which means that the efficiency is $100 \%$, instead of that of the Carnot factor, which will be very low according to the top and bottom temperatures.

\subsection{The reversible CC based on RBC-HCC}

The CC analysed in this section consists of a RBC as the primary cycle and a HCC as the secondary cycle referred to in Fig. 7. The data processed for both the primary and secondary cycles (the reversible RBC with helium as an ideal gas and the reversible HCC with helium as an ideal gas) is shown in Tables 5 and 6 . In Table 5 the parameters of the primary cycle of the CC composed of a non-regenerative reversible RBC with ideal helium are shown. In Table 6, the parameters of the secondary cycle of the CC composed of a nonregenerative reversible $\mathrm{HCC}$ operating with ideal helium are shown.

The analysis of the data shown in Tables 5 and 6 has been performed for the conditions with the highest performance as a function of the pR. The results of the analysis are displayed in Table 7. This Table depicts the power of the RBC compressor, the power of the RBC expander, the power of the HCC fan, the net power of the $\mathrm{CC}$, the pressure ratio, the power ratio, the mass flow rate of the RBC, the mass of hot-working fluid ( $\mathrm{M}_{-} \mathrm{HCCh}_{\text {) }}$ ) (ideal helium), the mass of cold-working fluid $\left(\mathrm{M}_{-} \mathrm{HCCC}\right)$, temperature differences between both sides of any heat exchanger, the flow rate of the $\mathrm{OBC}$ and the temperature difference of the heat exchangers.

Table 5. The parameters of the primary cycle of the CC composed of a reversible RBC with helium without regeneration

\begin{tabular}{lccccc}
\hline \multicolumn{6}{c}{$\mathrm{RBC}$} \\
\hline point & $\mathrm{T}_{\mathrm{i}}$ & $\mathrm{p}_{\mathrm{i}}$ & $\mathrm{h}_{\mathrm{i}}$ & $\mathrm{v}_{\mathrm{i}}$ & $\mathrm{s}_{\mathrm{i}}$ \\
& $\mathrm{K}$ & $\mathrm{kPa}$ & $\mathrm{kJ} / \mathrm{kg}$ & $\mathrm{m}^{3} / \mathrm{kg}$ & $\mathrm{kJ} / \mathrm{kg} \cdot \mathrm{K}$ \\
1 & 281.1 & 1000 & 1468 & 0.5869 & 22.92 \\
2 & 299.5 & 1172 & 1564 & 0.5338 & 22.92 \\
3 & 285.0 & 1172 & 1489 & 0.5081 & 22.66 \\
4 & 267.5 & 1000 & 1397 & 0.5586 & 22.66 \\
\hline
\end{tabular}


Table 6. The parameters of the secondary cycle of the CC composed of a reversible HCC without regeneration with helium as the working fluid.

\begin{tabular}{cccccccccccccc}
\hline \multicolumn{1}{c}{ HCC Cylinder chamber (A) } & \multicolumn{1}{c}{ HCC Cylinder chamber (B) } \\
\hline point & $\mathrm{T}$ & $\mathrm{p}$ & $\mathrm{u}$ & $\mathrm{v}$ & $\mathrm{s}$ & $\mathrm{h}$ & $\mathrm{T}$ & $\mathrm{p}$ & $\mathrm{u}$ & $\mathrm{v}$ & $\mathrm{s}$ & $\mathrm{h}$ \\
& $\mathrm{K}$ & $\mathrm{kPa}$ & $\mathrm{kJ} / \mathrm{kg}$ & $\mathrm{m}^{3} / \mathrm{kg}$ & $\mathrm{kJ} / \mathrm{kg} \cdot \mathrm{K}$ & $\mathrm{kJ} / \mathrm{kg}$ & $\mathrm{K}$ & $\mathrm{kPa}$ & $\mathrm{kJ} / \mathrm{kg}$ & $\mathrm{m}^{3} / \mathrm{kg}$ & $\mathrm{kJ} / \mathrm{kg} \cdot \mathrm{K}$ & $\mathrm{kJ} / \mathrm{kg}$ \\
& & & & & & & & & & & & & \\
1 & 282.6 & 1000.0 & 886.1 & 0.5901 & 22.95 & 1476 & 283.5 & 1000.0 & 888.7 & 0.5918 & 22.96 & 1480 \\
2 & 284.0 & 1005.0 & 890.4 & 0.5901 & 22.96 & 1483 & 282.1 & 995.2 & 884.4 & 0.5918 & 22.95 & 1473 \\
3 & 283.5 & 1000.0 & 888.7 & 0.5918 & 22.96 & 1480 & 282.6 & 1000.0 & 886.1 & 0.5901 & 22.95 & 1476 \\
4 & 283.5 & 1000.0 & 888.7 & 0.5918 & 22.96 & 1480 & 282.6 & 1000.0 & 886.1 & 0.5901 & 22.95 & 1476 \\
5 & 282.1 & 995.2 & 884.4 & 0.5918 & 22.95 & & 284.0 & 1005.0 & 890.4 & 0.5901 & 22.96 & \\
6 & 282.6 & 1000.0 & 886.1 & 0.5901 & 22.95 & & 283.5 & 1000.0 & 888.7 & 0.5918 & 22.96 & \\
\hline
\end{tabular}

Therefore, the net-work, $\mathrm{Wn}(\mathrm{RBC}-\mathrm{HCCC})$ of the reversible CC is defined as

$$
\begin{aligned}
& w_{n(R B C)}=w_{C R B C}-w_{E R B C} \\
& w_{n(H C C)}=w_{H C C}-w_{F H C C} \\
& w_{n(R B C-H C C)}=w_{C R B C}-w_{E R B C}+w_{H C C}-w_{F H C C}
\end{aligned}
$$

Although the cycle is reversible, the PR approaches 1,486 (148.6\%) instead of 1,00 which, according to conventional thermodynamics will be $100 \%$. This means that the thermal efficiency of the CC defined as conventional, is $148 \%$, instead of that of the Carnot factor, which will be very low according to the top and bottom temperatures of the heat source and heat sink generated by the RBC. According to these results, the CC produced energy instead of converting thermal energy. This result supposes a flagrant violation of the principle of energy conservation and consequently the violation of the first law of the thermodynamics. The consistence of the analysis has been verified according to the conventional theory of thermodynamics. This means that some modifications of the actual theory must be carried out in order to apply a coherent, consistent and robust theory to avoid such inconsistences. 


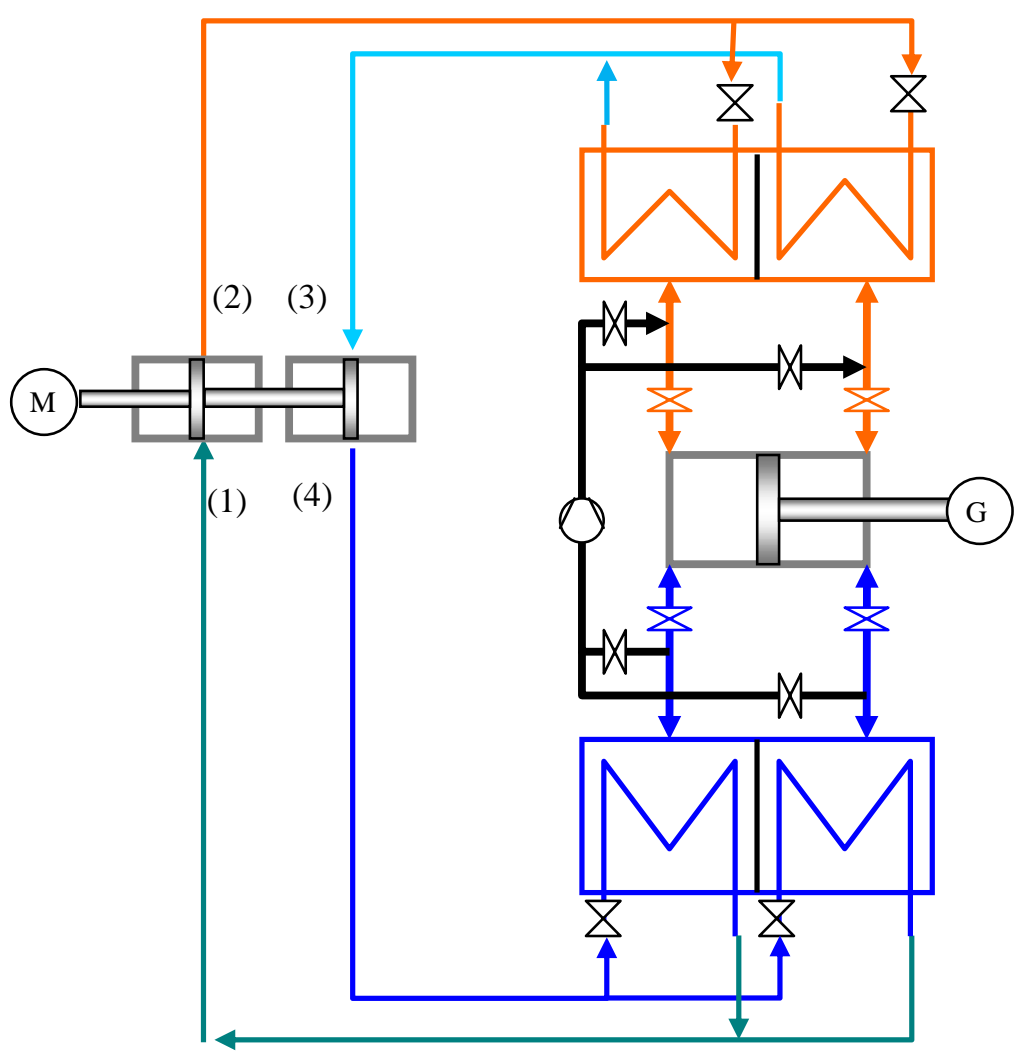

Fig. 7. Detailed structure of a reversible CC composed of a RBC and a non-conventional reciprocating engine $\mathrm{HCC}$ characterised by converting heat to work while heating and releasing heat.

Table 7. The results of the CC composed of a reversible RBC with helium and a reversible HCC with helium.

\begin{tabular}{ccccccccccc}
\hline$P_{C . R B C}$ & $P_{E . R B C}$ & $P_{H C C}$ & $P_{\text {F.HCC }}$ & $P_{\text {n.CC }}$ & pR & PR & $m_{\text {RBC }}$ & $M_{H C C h}$ & $M_{\text {HCCC }}$ & $d T$ \\
$k W$ & $k W$ & $k W$ & $k W$ & $k W$ & & & $k g / s$ & $k g / s$ & $k g / s$ & $K$ \\
6.77 & 91.55 & 58.41 & 4.71 & 49.07 & 1.172 & 1.486 & 1 & 17.79 & 16.72 & 1 \\
\hline
\end{tabular}

\subsection{The regenerative irreversible CC based on RBC-HCC}

Based on the incoherence of the results obtained in the previous section, it is questionable how much irreversibility must be added to this cycle so that its efficiency is equal to or less than $100 \%$ in order to fulfil the principle of conservation of energy. The $\mathrm{CC}$ analysed in this section consists of a regenerative irreversible RBC as the primary cycle and a regenerative irreversible HCC as the secondary cycle referred to in Fig. 8 . The data processed for both primary and secondary cycles (the regenerative irreversible RBC with helium as a real gas and the regenerative irreversible HCC operating with helium as a real gas) are shown in Tables 8 and 9. In Table 8 the parameters of the primary cycle of the CC composed of a regenerative irreversible RBC with helium as a real gas are shown. In Table 9, the parameters of the secondary cycle of the CC composed of a regenerative irreversible $\mathrm{HCC}$ operating with helium as a real gas are shown. The following irreversibilities are assumed: $\mathrm{I}_{\mathrm{TRBC}}=3 \% ; \mathrm{I}_{\mathrm{CRBC}}=3 \% ; \mathrm{I}_{\mathrm{HCC}}=3 \% ; \mathrm{I}_{\mathrm{FHCC}}=10 \%$. 
Table 8. The parameters of the primary cycle of the CC composed of a regenerative irreversible RBC with helium as a real gas.

\begin{tabular}{lccccc}
\hline point & $\mathrm{T}_{\mathrm{RBC}}$ & $\mathrm{p}_{\mathrm{RBC}}$ & $\mathrm{h}_{\mathrm{RBC}}$ & $\mathrm{V}_{\mathrm{RBC}}$ & $\mathrm{S}_{\mathrm{RBC}}$ \\
& $\mathrm{K}$ & $\mathrm{kPa}$ & $\mathrm{kJ} / \mathrm{kg}$ & $\mathrm{m}^{3} / \mathrm{kg}$ & $\mathrm{kJ} / \mathrm{kg} \cdot \mathrm{K}$ \\
1 & 290.0 & 1000 & 1514 & 0.6054 & 23.08 \\
2 & 326.8 & 1348 & 1707 & 0.5065 & 23.08 \\
3 & 300.0 & 1348 & 1568 & 0.4653 & 22.63 \\
4 & 295.0 & 1348 & 1542 & 0.4576 & 22.55 \\
5 & 261.8 & 1000 & 1368 & 0.5468 & 22.55 \\
6 & 285.0 & 1000 & 1488 & 0.5950 & 22.99 \\
\hline
\end{tabular}

Table 9. The parameters of the secondary cycle of the CC composed of a regenerative irreversible HCC with helium as a real gas.

\begin{tabular}{cccccccccccccc}
\hline \multicolumn{11}{c}{ HCC Cylinder chamber (A) } & \multicolumn{1}{c}{ HCC Cylinder chamber (B) } \\
\hline point & $\mathrm{T}_{\mathrm{i}}$ & $\mathrm{p}_{\mathrm{i}}$ & $\mathrm{u}_{\mathrm{i}}$ & $\mathrm{v}_{\mathrm{i}}$ & $\mathrm{s}_{\mathrm{i}}$ & $\mathrm{h}_{\mathrm{i}}$ & $\mathrm{T}_{\mathrm{i}}$ & $\mathrm{p}_{\mathrm{i}}$ & $\mathrm{u}_{\mathrm{i}}$ & $\mathrm{v}_{\mathrm{i}}$ & $\mathrm{s}_{\mathrm{i}}$ & $\mathrm{h}_{\mathrm{i}}$ \\
& $\mathrm{K}$ & $\mathrm{kPa}$ & $\mathrm{kJ} / \mathrm{kg}$ & $\mathrm{m}^{3} / \mathrm{kg}$ & $\mathrm{kJ} / \mathrm{kg} \cdot \mathrm{K}$ & $\mathrm{kJ} / \mathrm{kg}$ & $\mathrm{K}$ & $\mathrm{kPa}$ & $\mathrm{kJ} / \mathrm{kg}$ & $\mathrm{m}^{3} / \mathrm{kg}$ & $\mathrm{kJ} / \mathrm{kg} \cdot \mathrm{K}$ & $\mathrm{kJ} / \mathrm{kg}$ \\
& 291.4 & 1000.0 & 913.5 & 0.6083 & 23.10 & 1522 & 293.6 & 1000.0 & 920.2 & 0.6128 & 23.14 & 1533 \\
1 & 295.0 & 1012.0 & 924.6 & 0.6083 & 23.14 & 1540 & 290.0 & 987.9 & 909.1 & 0.6128 & 23.10 & 1514 \\
3 & 293.6 & 1000.0 & 920.2 & 0.6128 & 23.14 & 1533 & 291.4 & 1000.0 & 913.5 & 0.6083 & 23.10 & 1522 \\
4 & 293.6 & 1000.0 & 920.2 & 0.6128 & 23.14 & 1533 & 291.4 & 1000.0 & 913.5 & 0.6083 & 23.10 & 1522 \\
5 & 290.0 & 987.9 & 909.1 & 0.6128 & 23.10 & & 295.0 & 1012.0 & 924.6 & 0.6083 & 23.14 & \\
6 & 291.4 & 1000.0 & 913.5 & 0.6083 & 23.10 & & 293.6 & 1000.0 & 920.2 & 0.6128 & 23.14 & \\
\hline
\end{tabular}

The data shown in Tables 8 and 9 have been used to analyse the regenerative irreversible CC under the conditions with the highest performance as a function of the $\mathrm{pR}$. The results of the analysis are displayed in Table 10. In this Table, it is shown that the power of the irreversible RBC compressor, the power of the irreversible RBC expander, the power of the irreversible $\mathrm{HCC}$ fan, the net power of the irreversible CC, the $p R$, the PR, the mass flow rate of the irreversible RBC, the mass of hot working fluid ( $M_{-}$HCch $)$(real helium), the mass of cold working fluid $\left(\mathrm{M}_{-} \mathrm{HCCC}\right)$ and the temperature differences between both sides of the heat exchangers. 
In this part of the case study the cycle is irreversible, so that according to the results of the Table 10, the PR approaches 1,29 instead of 1,486 (the previous case, a reversible CC) which, according to conventional thermodynamics, will be less than $100 \%$ due to the irreversibilities. DO YOU MEAN 1.29 AND 1.486? This means that the thermal efficiency of the irreversible CC defined conventionally, is $129 \%$, instead of an efficiency less than 100\%. According to these results, the irreversible CC produced energy instead of converting thermal energy as occurred in the previous case. This result supposes a flagrant violation of the principle of energy conservation and consequently a violation of the first law of the thermodynamics. Such a surprising result contradicts the expected results when using the conventional thermodynamic analysis methodology, mainly because the consistency of the analysis has been verified according to conventional theory of thermodynamics. This means that some modifications of the actual theory must be carried out in order to apply a coherent, consistent and robust theory in order to avoid such inconsistences. In any case, is the consideration of the possibility of creating instead of converting energy coherent?

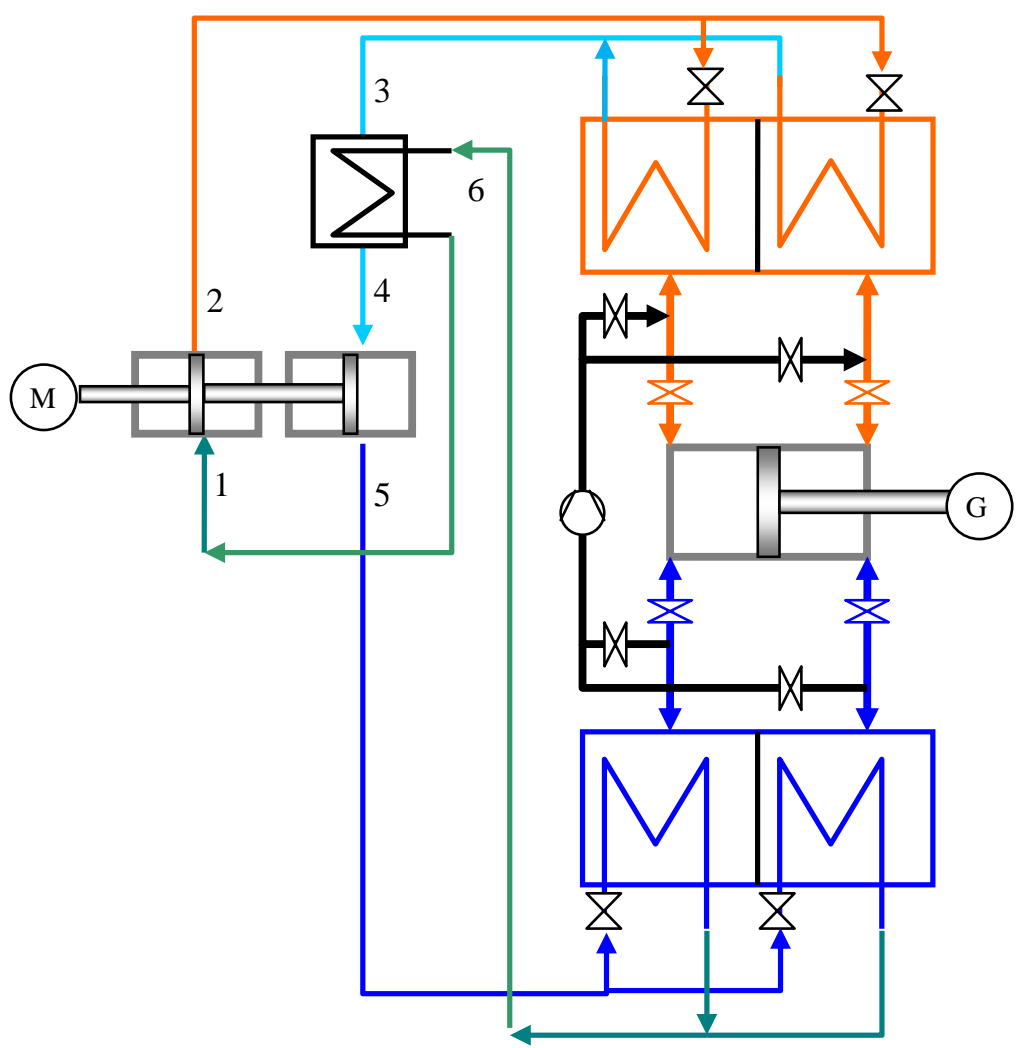

Fig. 8. Detailed structure of a CC composed of a regenerative irreversible RBC based on a reciprocating compressor and expander, and a non-conventional reciprocating engine HCC characterized by converting heat to work during heating and the release of heat.

Table 10. The results of the CC composed of an irreversible RBC with helium and a regenerative irreversible $\mathrm{HCC}$ with helium as a real gas, where the assumed irreversibilities are $\mathrm{I}_{\mathrm{TRBC}}=3 \% ; \mathrm{I}_{\mathrm{CRBC}}=3 \% ; \mathrm{I}_{\mathrm{HCC}}=3 \% ; \mathrm{I}_{\mathrm{FHCC}}=10 \%$.

\begin{tabular}{ccccccccccc}
\hline$P_{C . R B C}$ & $P_{E . R B C}$ & $P_{H C C}$ & $P_{F . H C C}$ & $P_{n . C C}$ & $p R$ & $P R$ & $m_{R B C}$ & $M_{H C C h}$ & $M_{H C C C}$ & $d T$ \\
$k W$ & $k W$ & $k W$ & $k W$ & $k W$ & & & $k g / s$ & $k g / s$ & $k g / s$ & $k$ \\
17.81 & 166.3 & 100.6 & 10.53 & 60.41 & 1.348 & 1.29 & 1 & 12.45 & 10.84 & 5
\end{tabular}

According to (28), the net specific power, $P n(\mathrm{~kW} / \mathrm{kg})$, assuming irreversibilities that yield $\mathrm{I}_{\mathrm{TRBC}}{ }^{+}$ $\mathrm{I}_{\mathrm{CRBC}}+\mathrm{I}_{\mathrm{HCC}}+\mathrm{I}_{\mathrm{FHCC}}=19 \%$, for a PR of 1.348 , approaches $60.41 \mathrm{~kW}$ per $\mathrm{kg}$ of $\mathrm{m}_{\mathrm{RBC}}$. 


\section{Analysis and discussion of results}

The study of the previous section gives rise to controversial results because they contradict the fundamental laws. Thus, such controversial data needs in-depth analysis to clarify the observed inconsistencies as far as possible. The main results are extracted from Tables 4, 7 and 10, which are included in Table 11 and mainly concern the violation of the fundamental laws.

Therefore, the causes of such controversial results obey:

- the generation of high- and low-temperature reservoirs (heat source and heat sink) by means of a RBC;

- the conversion of heat to work by releasing heat.

Table 11. The most relevant results of the case stud

\begin{tabular}{ccccccc}
\hline CC type & \multicolumn{2}{c}{ Reversible RBC-ORC } & \multicolumn{2}{c}{ Reversible RBC-HCC } & \multicolumn{2}{l}{ Reg-Irrev-RBC-HCC } \\
parameter & $\mathrm{pR}$ & $\mathrm{PR}$ & $\mathrm{pR}$ & $\mathrm{PR}$ & $\mathrm{pR}$ & $\mathrm{PR}$ \\
value & 1.32 & 1 & 1.172 & 1.486 & 1.348 & 1.29
\end{tabular}

Observing the CC based on the reversible RBC-ORC follows that according to the results depicted by Table 11 the thermal efficiency is 1 or $100 \%$, under a pressure ratio of 1.32 , which surpasses the Carnot factor with a conventional thermal engine such as the reversible ORC. However, observing the CC based on the reversible RBC-HCC follows that according to the Table 11 , the thermal efficiency or power ratio is 1.486 or $148.6 \%$, under a pressure ratio of 1.172 , resulting in "created energy"; this is a controversial result that violates the principle of conservation of energy. Nevertheless, in the CC based on the regenerative and irreversible RBCHCC it follows that according to the last two columns of Table 11, the PR is 1.29 under a pR of 1.348, which also leads to "created energy" and thus violates the principle of conservation of energy.

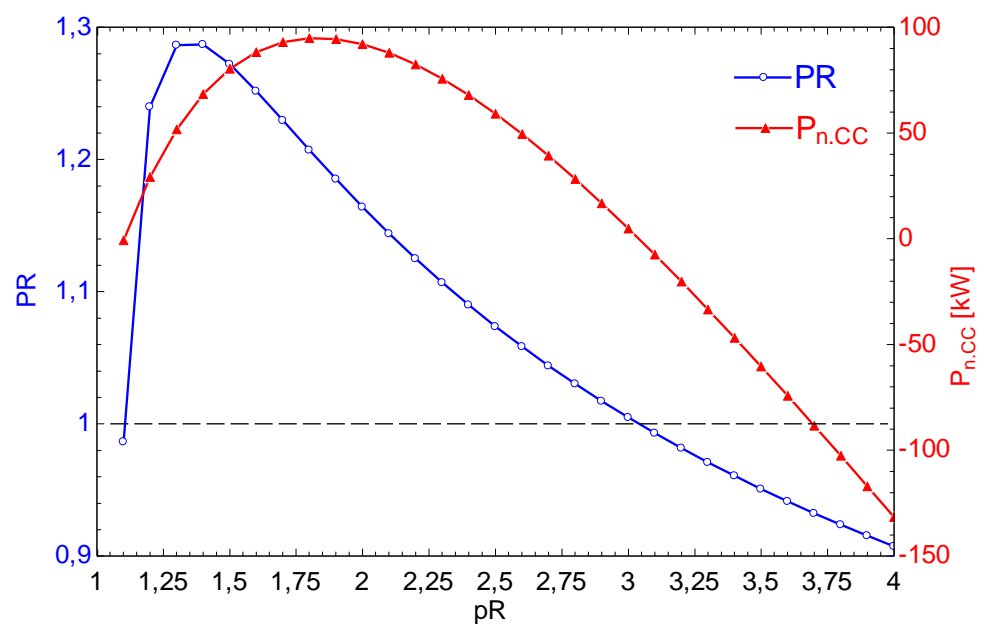

Fig. 9. The range of the $p R$ of a regenerative irreversible $C C$ composed of the regenerative irreversible RBC$\mathrm{HCC}$ in which energy was theoretically created.

In this way, we consider it interesting to estimate the range of pRs undergoing a given estimated irreversibility assigned to the CC of $\left(I_{T R B C}+I_{C R B C}+I_{H C C}+I_{F H C C}=19 \%\right)$, to find out a range of the pRs into which energy could be theoretically created (not converted), where the following irreversibilities are assumed: $I_{T R B C}=3 \%$; $I_{C R B C}=3 \%$; $I_{H C C}=3 \% ; I_{F H C C}=10 \%$. Thus, Fig. 9 shows the range of $p R s$ assigned to the $\mathrm{CC}$ composed of a regenerative irreversible RBC-HCC in which energy was theoretically created. It is worth noting the range of irreversibilities 
assigned to the CC into which energy is generated instead of converted. As shown in Fig. 10, according to the prospection of the results of a scan, the regenerative irreversible CC generates energy in the range $0-19 \%$, while converts energy in the rest of the viable operating range.

\subsection{The influence of the analysis results on the second law statements}

In the section 2.1 it has been said that the statements involving the $2^{\text {nd }}$ law express the conditions that satisfy the heat transfer properties. Thus, Clausius' statement stated, "it is impossible for any system to operate in such a way that the sole result would be an energy transfer by heat from a cooler to a hotter body". Furthermore, such statement undergoes the meaning: "it is impossible to construct a device that operates in a cycle and produces no effect other than the transfer of heat from a lower-temperature body to a higher-temperature body". However, according to the results of the analysis, this statement is only partially true, under the condition that energy could be created as shown in Fig. 9, where if energy can be created, then this statement is violated fragrantly, since it transfer heat from a cold reservoir to a hotter reservoir without any external help.

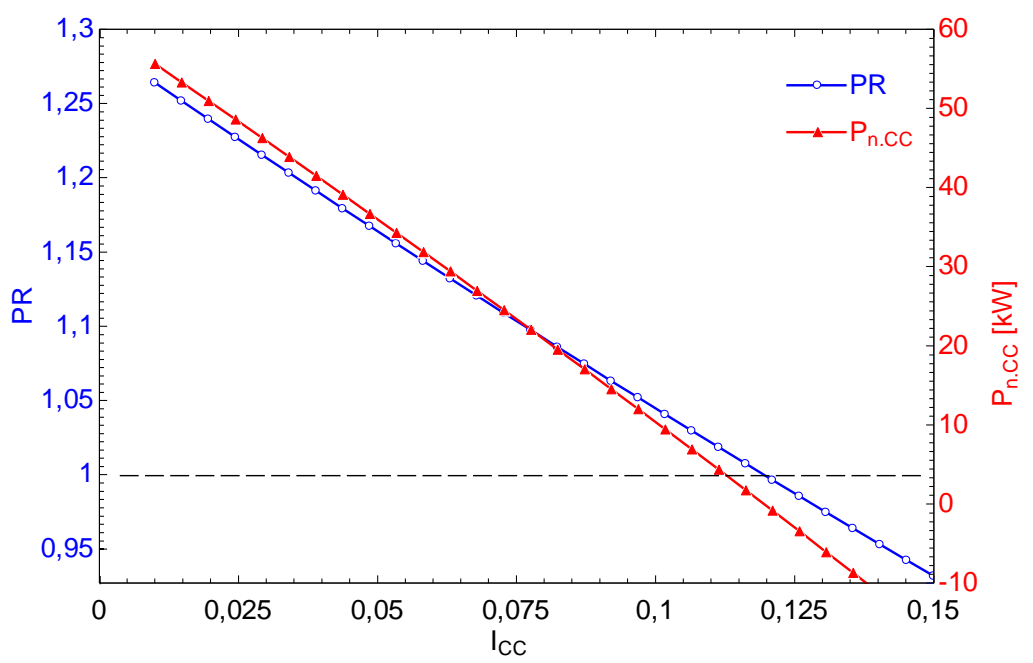

Fig. 10. The range of irreversibilities of the CC composed of the regenerative irreversible RBC-HCC in which energy was theoretically created as a function of the percentage of irreversibilities.

The results shown in Fig.9 derived from the plant structure depicted in Fig. 3, means that the Clausius statement cannot be satisfied since it behaves like a heat pump that provides more thermal energy than it absorbs, which is a flagrant violation of the $2^{\text {nd }}$ law.

Furthermore, Kelvin-Planck stated, "It is impossible for any device that operates on a cycle to receive heat from a single reservoir and produce a net amount of work". However, according to the last advances based on doing work by releasing heat as shown in $[1,2,16]$, an amendment to the Kelvin-Plank statement is necessary, just to correct the contribution of doing work while releasing heat to a heat sink.

Amended Kelvin-Planck Statement: It is impossible for any device that operates on a cycle to release heat into a single reservoir and produce a net amount of work.

Although the Clausius and Kelvin-Planck statements are equivalent, the proposed extension of the KelvinPlank statement above does not contradict such equivalence.

\section{Conclusions}

In order to highlight and clarify the concepts of energy generation versus energy conversion, the study of a feasible case based on two combined cycles where the first one is based on a reversible RBC-ORC and the 
second one is based on a reversible RBC-HCC cycle was performed. In this study, it has been shown that such a case is particularly interesting since the reverse Brayton cycle as the primary cycle is responsible for providing the hot and cold heat sinks of the secondary cycle. Also, such a combination of thermal cycles shows us that energy can be converted and/or theoretically generated, which means a obtaining theoretical net energy without contributing with any type of energy. According to the discussion of results, for the reversible CC based on the RBC-ORC the maximum obtained power is $100 \%$ as expected. It is a consistent result since no violation of any fundamental law is produced. However, in the case of the reversible CC based on the RBC$\mathrm{HCC}$, we are facing the paradigmatic case of energy generation, which violates the principle of energy conservation: the theoretical energy balance provides more energy than it absorbs. Given such a controversial result that seems absurd, we must ask how much irreversibility must be attributed to the combined cycle so as to avoid the violation of the principle of energy conservation. The result is derived form a search or tracing of the thermodynamic model of the combined cycle, having assumed a rate of irreversibility sufficiently representative of a real viable cycle.

The case study based on a reverse Brayton cycle with a heating-cooling based cycle, is the paradigm of the energy generation in contrast with the energy conversion that yields a 1.486 PR or is $148.6 \%$ efficient. The case study based on a reverse Brayton cycle with a regenerative irreversible heating-cooling based cycle, is the paradigm of energy conversion and energy generation that yields a 1.29 PR that means an efficiency of $129 \%$.

\section{References}

[1] Ferreiro Garcia R. Contributions on Closed System Transformations Based Thermal Cycles. British Journal of Applied Science and Technology (BJAST) 2014; 4:2821-2836. doi:10.9734/bjast/2014/10074.

[2] Ferreiro Garcia R. Preliminary Study of an Efficient OTEC Using a Thermal Cycle with Closed Thermodynamic Transformations. British Journal of Applied Science and Technology (BJAST) 2014; 4:3840-3855. doi:10.9734/bjast/2014/11152.

[3] Ferreiro Garcia R, Sanz B, Sanz C. Power Plant Driven by Residual Heat Rejected by the Secondary Low Pressure Steam Turbines. British Journal of Applied Science and Technology (BJAST) 2015;6:216-228. doi:10.9734/bjast/2015/12111.

[4] Ferreiro Garcia R, Sanz B, Sanz C. Isothermal and Adiabatic Expansion based Trilñateral Cycles. British Journal of Applied Science and Technology (BJAST) 2015;8(5): 448-460. doi:10.9734/bjast/2015/12111.

[5] Ferreiro Garcia R, Sanz B. The Behaviour of Some Working Fluids Applied on the Trilateral Cycles with Isothermal Controlled Expansion. British Journal of Applied Science and Technology (BJAST) 2015;9:450-463. doi:10.9734/bjast/2015/18624.

[6] Ferreiro Garcia R, Carril JC, Gomez JR, Gomez MR. Preliminary thermodynamic study of regenerative Otto based cycles with zero NOx emissions operating with adiabatic and polytropic expansion. Energy Conversion and Management 2016; 113: 252-263. http://dx.doi.org/10.1016/j.enconman.2016.01.066.

[7] Ferreiro Garcia R, Carril JC, Gomez JR, Gomez MR. Energy and entropy analysis of closed adiabatic expansion based trilateral cycles. Energy Conversion and Management 2016;119:49-59. doi:10.1016/j.enconman.2016.04.031.

[8] Xiaohui S., Yonggao Y., Xiaosong Z., Thermodynamic analysis of a novel energy-efficient refrigeration system subcooled by liquid desiccant dehumidification and evaporation. Energy Conversion and Management. 2014;78: 286-296. 
[9] Mandegari M, Farzad S, Pahlavanzadeh H. Exergy performance analysis and optimization of a desiccant wheel system. J. Therm. Sci. Eng. App. 2015;7: 3101301-3101310.

[10] Jani DB, Mishra M, Sahoo PK. Exergy analysis of solid desiccant-vapour compression hybrid air conditioning system. Int. J. Exergy. 2016; 20(4):517-535.

[11] Min-Hwi Kim, Jun-Seok Park, Jae-Weon Jeong, Energy saving potential of liquid desiccant in evaporative cooling-assisted 100 (\%) outdoor air system. Energy 2013; 59:726-736.

[12] Li Yinglin, Zhang Xiaosong, Tan Laizai, Zhang Zhongbin, Wu Wei, Xia Xueying. Performance analysis of a novel liquid desiccant-vapour compression hybrid air-conditioning system. Energy 2016; 109: 180-189.

[13] X. Cui, M.R. Islam, B. Mohan, K.J. Chua. Theoretical analysis of a liquid desiccant based indirect evaporative cooling system. Energy 2016; 95: 303-312.

[14] David Van Den Einde, The supercritical solvent thermal cycles: A challenge to the second law, Physics Essays. 2010; 23(4):550-553.

[15] David Van Den Einde, A potential for complete Rankine cycle exhaust heat regeneration, Physics Essays. 2016; 29(3):297-300.

[16] Ferreiro Garcia R., Carbia Carril J., Iglesias Garcia S., Low-grade heat-based thermal cycles unconstrained by the Carnot factor doing work by cooling, Energy, 122 (2017)204-213.

[17] Lemmon E. W., Huber M. L., and McLinden M. O. NIST Reference Fluid Thermodynamic and Transport Properties - REFPROP Version 8.0, User's Guide, NIST 2007, Boulder, Colorado. 